\title{
Availability analysis of thermal power plant boiler air circulation system using Markov approach
}

\author{
Ravinder Kumar*
}

Research Scholar, Department of Mechanical Engineering, D.C.R University of Science \& Technology Sonepat, India

\section{H R O N I C L E}

Article history:

Received September 15, 2012

Accepted Feb 25, 2013

Available online

August 22013

Keywords:

Markov Birth-Death process

Steady state availability

Probabilistic approach

Thermal power plant

\section{A B S T R A C T}

\begin{abstract}
The long term operation and planning of power plant depend upon an effective availability analysis and assessment of various systems in the plant concerned. The plant is expected to remain operational in a continual manner to achieve the desired production targets. Hence, the availability analysis of the boiler air circulation system plays an important role in this direction. For this purpose, the concerned system mathematical model based on Markov Birth-Death process has been developed. The system consists of four subsystems. The transition diagram represents reduced capacity, full working and failed state of the system. The differential equations associated with the transition diagram based on probabilistic approach have been solved recursively in order to develop the system steady state availability. Availability matrices represented measures the performance of the system concerned. In addition, different combinations of failures and repair rates provide various availability levels of the system. Maintenance decisions are taken based upon these values for improving availability of the power plant as well as the power supply. The result shows that the failure of the primary air fan affects the system availability at most, while failure of air heater affect it at least for different failures and repair rate combination of subsystems under study.
\end{abstract}

\section{Introduction}

In the present era of automation and modernization, setting up of production plants like thermal power plant involves a huge capital investment. Tan and Kramer (1997), analyzed that the unexpected shutdown of the plant can lose revenue ranges from $\$ 500-\$ 100000$ per hour. According to Abdelaziz (1997), for the long-term operation and planning of power plant, effective reliability analysis and assessment is the crucial factors to be observed. Galikowsky et al. (1996) presented that the failure-free operation of production systems seems to be not possible. However, the failures can be minimized by providing sufficient redundancy of the system. Gupta et al. (2005, 2007), stated that in order to bring the failed system back to functioning states, several imperfect repairs may be allowed to save time and expenses. The reuse of the old unit after repair is almost mandatory because replacement by a new unit is the costliest solution. Lieberman (1973), described that a probabilistic

* Corresponding author.

E-mail addresses: rav.chauhan@yahoo.co.in (Ravinder Kumar) 
analysis generally helps in the design improvement of system for minimum failure under given operating conditions. The main factors for component degradation are corrosion, wear, crack and fatigue, according to Clifton (1974). In the past, several mathematical models, have been developed, which helps in the prediction of availability. Most of these models are based on the Markov BirthDeath process. Shayan (1986) made a probabilistic model of coal-burning power plant. Kumar and Singh, Pandey and Kumar (1990) discussed the reliability and availability of fertilizer industry. As far as possible for efficient functioning, various systems of the plant remain in upstate according to Kumar and Pandey (1993).

Arora and Kumar (1997) presented a model based on Markov birth-death process for steam and power generation system availability analysis in thermal power plant. Cochran, Murugan and Krishnamurthy (2001), described generic Markov chains to evaluate the reliability parameters of a complex system of machinery in an oil refinery. Blischke and Murthy (2003) discussed basic concepts and issues in reliability, maintenance, maintainability and quality. According to barabady and Kumar (2007) system reliability and availability are the most important performance measures. Sharma and Tewari (2009) have presented a simplistic formulation for performance evaluation and economic analysis of thermal plant (based on redundancy approach) of the overall thermal power plant. Purbolaksono et al. (2010) used computer simulations for case studies of SA213-T22 steel tubes failure of boiler reheater and superheater. Garg et al. (2010) proposed a model for availability and maintenance scheduling of a repairable block-board manufacturing system. The model discussed helps in calculating both time dependent and steady state availability under idealized as well as faulty Preventive Maintenance (PM). Haghifam and Manbachi (2011) suggested reliability and availability modeling of combined heat and power systems.

Kumar et al. (2012) developed an availability simulation model for power generation system in a thermal power plant. Thus, availability analysis plays a key role in engineering design and has been effectively applied to enhance system performance. The long run availability analysis of an industry can help its management to understand the effects of increasing/decreasing the repair and failure rates of a particular component or sub-system on the overall availability of the system. To achieve long run availability, the units should be remaining operative for the maximum possible duration. So to achieve high production and good quality, there should be highest system availability for which maintenance operations should be managed well. For boiler air circulation system two nos. of trisector type re-generative air pre-heaters (A.P.H) are provided for primary and secondary air heating using waste heat from flue gases. The air is sucked from atmosphere through forced draft (F.D.) fans passes over the air heaters and enters into the furnace. The boiler is provided with three nos. of primary air (P.A.) fans, each fan being capable of catering total air requirement of mills. The hot air from primary air fans goes to primary air distribution headers where the coal is transported from primary air feeders to furnace coal bunkers. Flue gases from the furnace are passed to the chimney through induced draft (I.D.) fans. The complexity of equipment increasing day by day due to the continuous advancement in technology and automation in manufacturing. Hence, the equipment availability has come into focus. So, all the working engineering systems are expected to remain operationally with maximum efficiency for the maximum duration.

\section{System description}

The boiler air circulation system consists of four sub-systems: $P_{f}$ : Primary air fans, $F_{f}$ : Forced draft fans, $A_{h}$ : Air heaters, $I_{f}$ : Induced draft fans

\subsection{Assumptions}

1. A repaired unit is as good as new one.

2. Failure and repair rates for each subsystem are constant.

3. The standby units are totally similar to active ones. 
4. Not more than one failure occurs at a time.

\subsection{Nomenclature}

$\bigcirc$ : Good capacity state $\bigcirc$ : Reduced capacity state $\square$ : Failed state

$P_{f}, F_{f}, A_{h}, I_{f}:$ Subsystems are in good operating state

$p_{f}, f_{f}, a_{h}, i_{f}$ : Indicates the failed state of $P_{f}, F_{f}, A_{h}, I_{f}$

$\bar{P}_{f}, \bar{F}_{f}, \bar{A}_{h}, \bar{I}_{f}:$ Subsystems $P_{f}, F_{f}, A_{h}, I_{f}$ are in reduced capacity state

$f_{P_{f}}, f_{F_{f}}, f_{A_{h}}, f_{I_{f}}:$ Mean constant failure rates from states $P_{f}, F_{f}, A_{h}, I_{f}, \bar{P}_{f}, \bar{F}_{f}, \bar{A}_{h}, \bar{I}_{f}$ to the states $\bar{P}_{f}, \bar{F}_{f}, \bar{A}_{h}, \bar{I}_{f}, p_{f}, f_{f}, a_{h}, i_{f}$

$r_{P_{f}}, r_{F_{f}}, r_{A_{h}}, r_{I_{f}}$ : Mean constant repair rates from states $\bar{P}_{f}, \bar{F}_{f}, \bar{A}_{h}, \bar{I}_{f}, p_{f}, f_{f}, a_{h}, i_{f}$ to the states $P_{f}, F_{f}, A_{h}, I_{f}, \bar{P}_{f}, \bar{F}_{f}, \bar{A}_{h}, \bar{I}_{f}$

$P_{i}(t)$ : Probability that at time ' $\mathrm{t}$ ' the system is in $\mathrm{i}^{\text {th }}$ state.

' : Derivative w.r.t. 't'

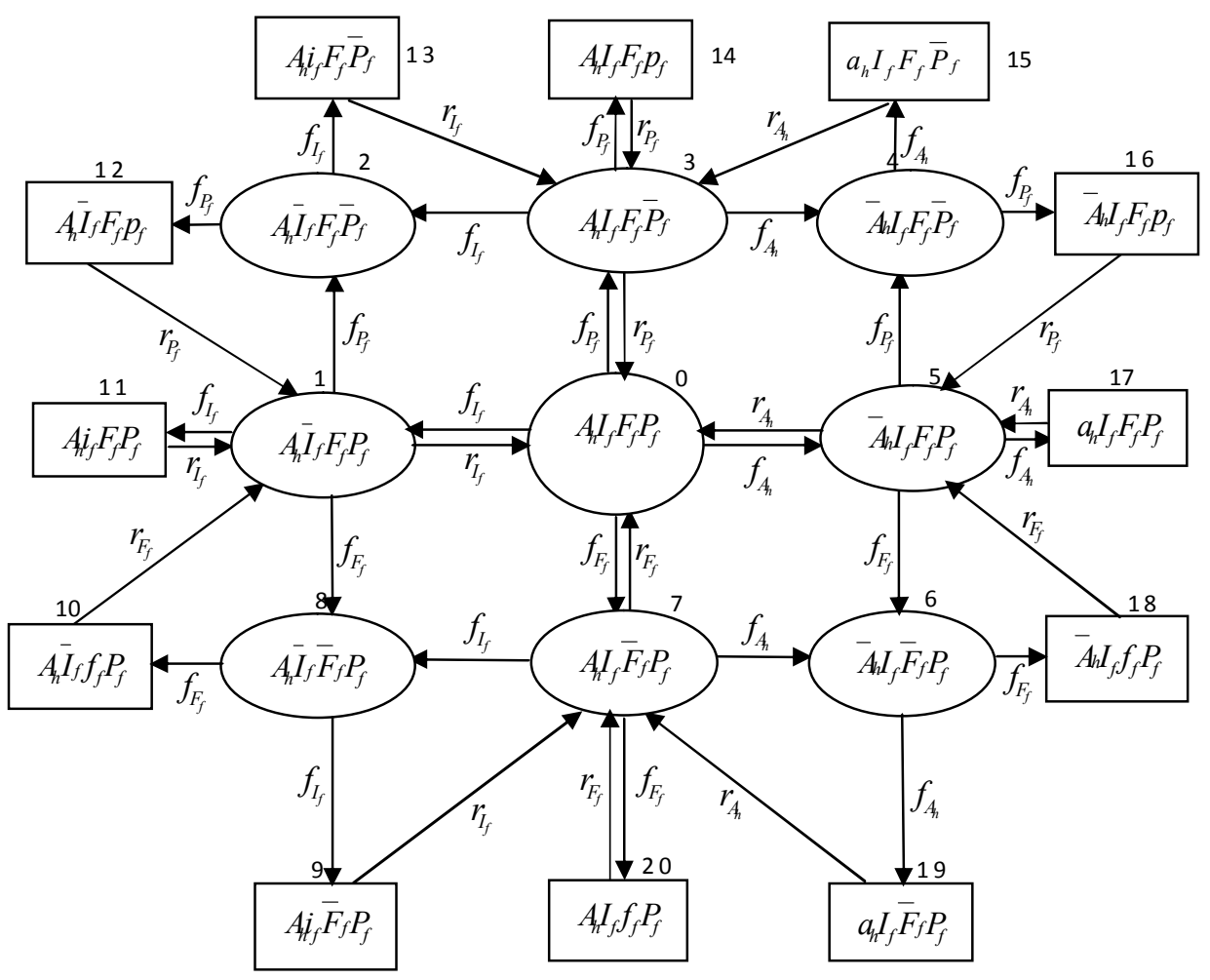

Fig. 1. Transition Diagram of Boiler air circulation system

\subsection{Formulation}

The formulation of operational availability of boiler air circulation system based on the Markovprocess approach. Fig. 1 gives the transition diagram for the boiler air circulation system. It includes total 21 states (' 0 ' to ' 20 ') out of which state ' 0 ' represents the success with full capacity, 8 states (i.e., ' 1 ' to ' 8 ') designate the success with reduced capacity, while 12 states (i.e., '9' to '20') represent to failed state in the transition diagram (refer fig. 1). Probability consideration relates the 
multistate transition diagram by 21 differential equations using Laplace transformation technique. System of differential equations has been closed recursively as described briefly in Appendix-A. Finally, the steady state availability of the boiler air circulation system can be obtained by adding all working state probabilities as

$$
(A v .)=\left(1+L_{1}+L_{2}+L_{3}+L_{4}+L_{5}+L_{6}+L_{7}+L_{8}\right) P_{0}
$$

The values of $\mathrm{P}_{0}$ and $\mathrm{L}_{1}-\mathrm{L}_{8}$ have been reported in Appendix-A.

\section{Results and discussion}

Table 1, 2, 3, 4 represent the availability matrices for various subsystems of the boiler air circulation system. Accordingly, best possible combinations of failure and repair rates of various subsystems can be chosen for maintenance planning. Tables 1 to $5 \&$ figures 2 to 5 shows the effect of failure and repair rates of Primary air fan, Forced draft fan, Air heater \& Induced draft fan on the steady state availability of the system. Table $1 \&$ figure 2 reveals the effect of failure and repair rates of Air heater subsystem on the availability of the system. It is observed that for some known values of failure/repair rates of Primary air fans, Forced draft fans \& Induced draft fans $\left(\lambda_{2}=0.0001, \lambda_{3}=\right.$ $\left.0.00005, \lambda_{4}=0.001, \mu_{2}=0.002, \mu_{3}=0.02, \mu_{4}=0.01\right)$, as the failure rates of Air heater increases from 0.0008 to 0.0024 the availability decreases by about $1.3 \%$. Similarly as repair rates of Air heater increases from 0.025 to 0.045 , the availability increases by about $0.001 \%$. Similarly for other subsystems like Primary air fans, Forced draft fans \& Induced draft fans the results has been represented by Tables 3 to 4 and graphically by figures 3 to 5 . Accordingly, maintenance decisions can be made for various subsystems keeping in view the repair criticality and we may select the best possible combinations of failure and repair rates.

Table 1

Effect of Failure and Repair Rates of Air heater on Availability $\left(A_{v}\right) \rightarrow$

\begin{tabular}{lllllll}
\hline & \multicolumn{5}{c}{$\lambda_{1}$} & \\
\cline { 2 - 5 }$\mu_{1}$ & & \multicolumn{5}{c}{ Constant values } \\
0.025 & 0.9008 & 0.0012 & 0.0016 & 0.0020 & 0.0024 & \\
0.030 & 0.984298 & 0.981852 & 0.979348 & 0.976727 & 0.973964 & $\lambda_{2}=0.0001, \mu_{2}=0.02$, \\
0.035 & 0.984801 & 0.982721 & 0.980643 & 0.978501 & 0.976265 & $\lambda_{3}=0.00005, \mu_{3}=0.02$, \\
0.040 & 0.985157 & 0.983332 & 0.981549 & 0.979738 & 0.977867 & $\lambda_{4}=0.001, \mu_{4}=0.01$ \\
0.045 & 0.985422 & 0.983782 & 0.982213 & 0.980643 & 0.979036 & \\
\hline
\end{tabular}

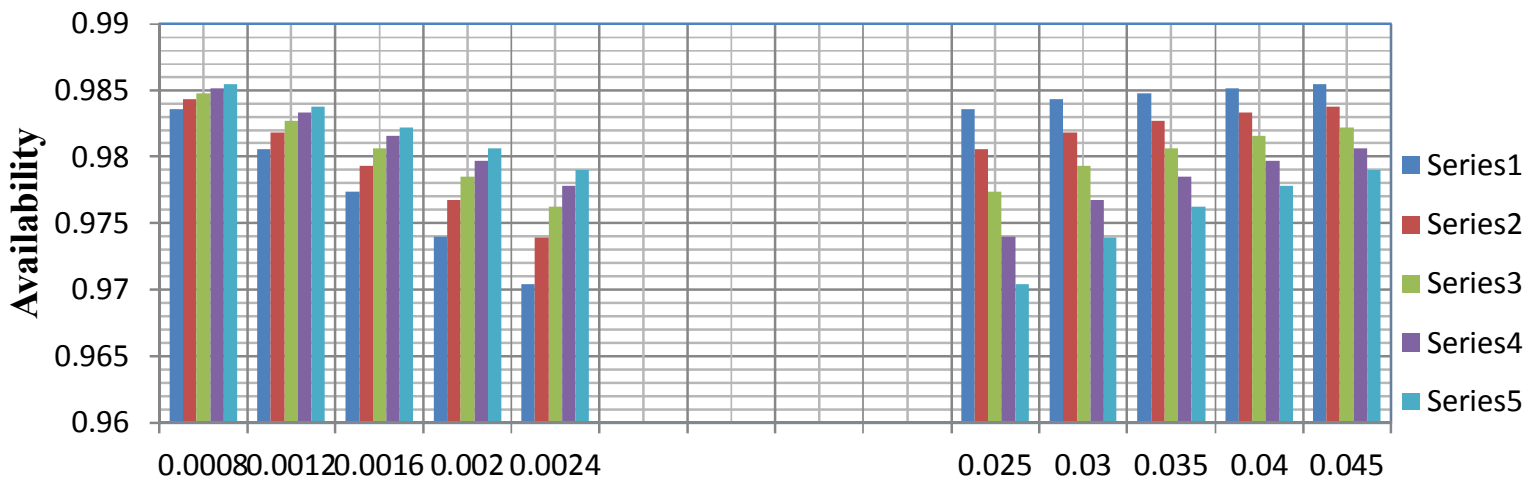

Failure rate

Repair rate

Fig. 2. Effect of Failure and Repair Rates of Air heater $\left(A_{h}\right)$ on Availability $\left(A_{v}\right)$ 
Table 2

Effect of Failure and Repair Rates of Induced Draft Fan on Availability $\left(\mathrm{A}_{\mathrm{v} .}\right) \rightarrow$

\begin{tabular}{ccccccl}
\hline \multicolumn{7}{c}{$\lambda_{2}$} \\
$\mu_{2}$ & & & & & \\
0.02 & 0.983540 & 0.982726 & 0.981921 & 0.981117 & 0.980309 & \\
0.03 & 0.983660 & 0.983008 & 0.982397 & 0.981814 & 0.981250 & $\lambda_{1}=0.0008, \mu_{1}=0.025$, \\
0.04 & 0.983717 & 0.983137 & 0.982609 & 0.982120 & 0.981659 & $\lambda_{3}=0.00005, \mu_{3}=0.02$, \\
0.05 & 0.983749 & 0.983210 & 0.982728 & 0.982289 & 0.981883 & $\lambda_{4}=0.001, \mu_{4}=0.01$ \\
0.06 & 0.983771 & 0.983257 & 0.982804 & 0.982396 & 0.982024 & \\
\hline
\end{tabular}

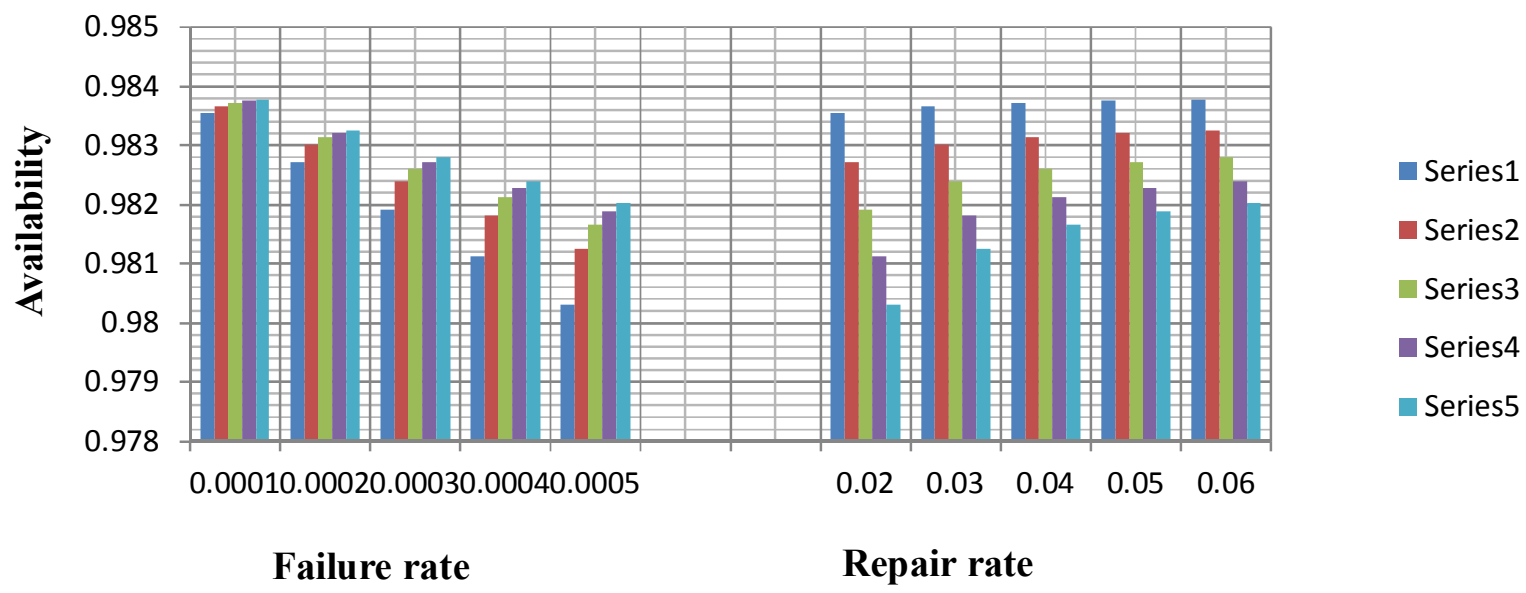

Fig. 3. Effect of Failure and Repair Rates of Induced Draft Fan $\left(I_{d}\right)$ on Availability $\left(A_{v}\right)$

Table 2

Effect of Failure and Repair Rates of Forced Draft Fan on Availability $\left(\mathrm{A}_{\mathrm{v}}\right) \rightarrow$

\begin{tabular}{|c|c|c|c|c|c|c|}
\hline & & & $\lambda_{3}$ & & & \\
\hline 0.02 & 0.983540 & 0.983494 & 0.983420 & 0.983325 & 0.983212 & \multirow{5}{*}{$\begin{array}{l}\lambda_{1}=0.0008, \mu_{1}=0.025, \\
\lambda_{2}=0.0001, \mu_{2}=0.02 \\
\lambda_{4}=0.001, \mu_{4}=0.01\end{array}$} \\
\hline 0.03 & 0.983544 & 0.983517 & 0.983476 & 0.983424 & 0.983363 & \\
\hline 0.04 & 0.983544 & 0.983525 & 0.983496 & 0.983460 & 0.983419 & \\
\hline 0.05 & 0.983544 & 0.983528 & 0.983505 & 0.983477 & 0.983446 & \\
\hline 0.06 & 0.983544 & 0.983530 & 0.983510 & 0.983487 & 0.983461 & \\
\hline
\end{tabular}

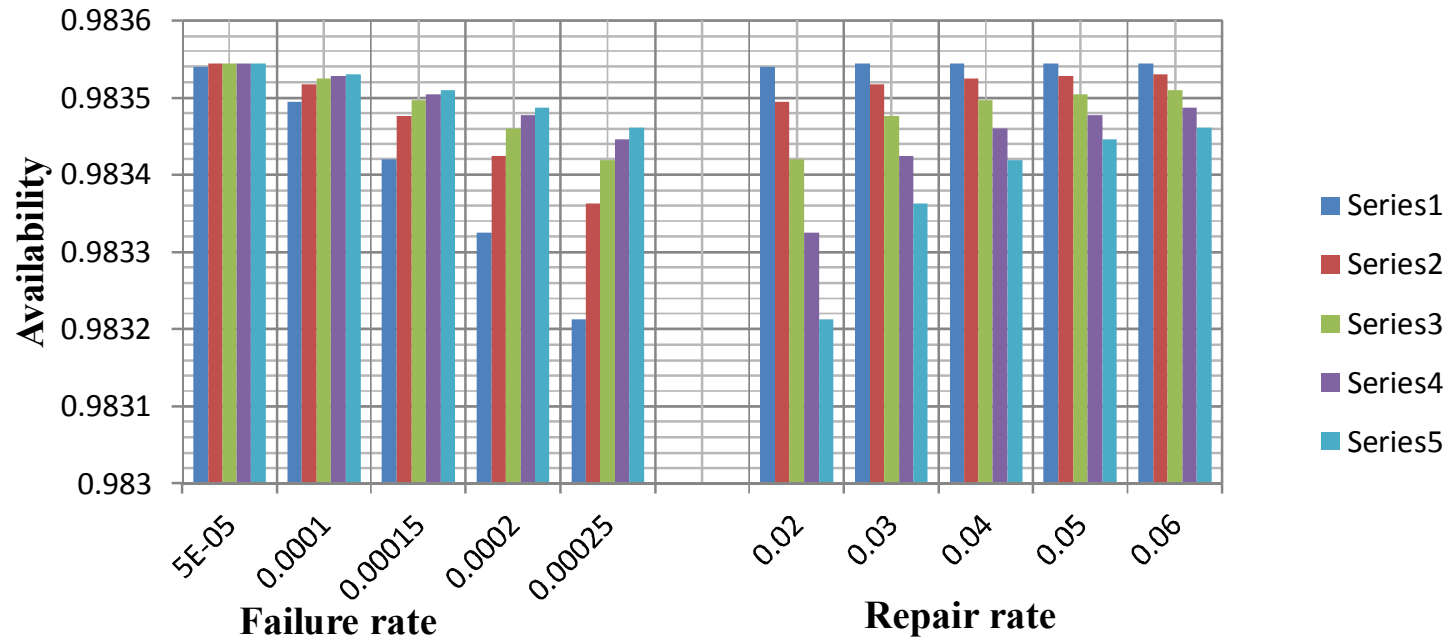

Fig. 4: Effect of Failure and Repair Rates of Forced Draft Fan on Availability $\left(\mathrm{A}_{\mathrm{v} .}\right)$ 
Table 4

Effect of Failure and Repair Rates of Primary Air Fan on Availability $\left(\mathrm{A}_{\mathrm{v} .}\right) \rightarrow$

\begin{tabular}{|c|c|c|c|c|c|c|}
\hline 0.01 & 0.983540 & 0.956546 & 0.922968 & 0.885799 & 0.847130 & \multirow{5}{*}{$\begin{array}{l}\lambda_{1}=0.0008, \mu_{1}=0.025, \\
\lambda_{2}=0.0001, \mu_{2}=0.02, \\
\lambda_{3}=0.00005, \mu_{3}=0.02\end{array}$} \\
\hline 0.02 & 0.993510 & 0.984587 & 0.972812 & 0.958750 & 0.942890 & \\
\hline 0.03 & 0.995774 & 0.991156 & 0.985072 & 0.977689 & 0.969173 & \\
\hline 0.04 & 0.996672 & 0.993748 & 0.989957 & 0.985353 & 0.980006 & \\
\hline 0.05 & 0.997132 & 0.995056 & 0.992422 & 0.989239 & 0.985538 & \\
\hline
\end{tabular}

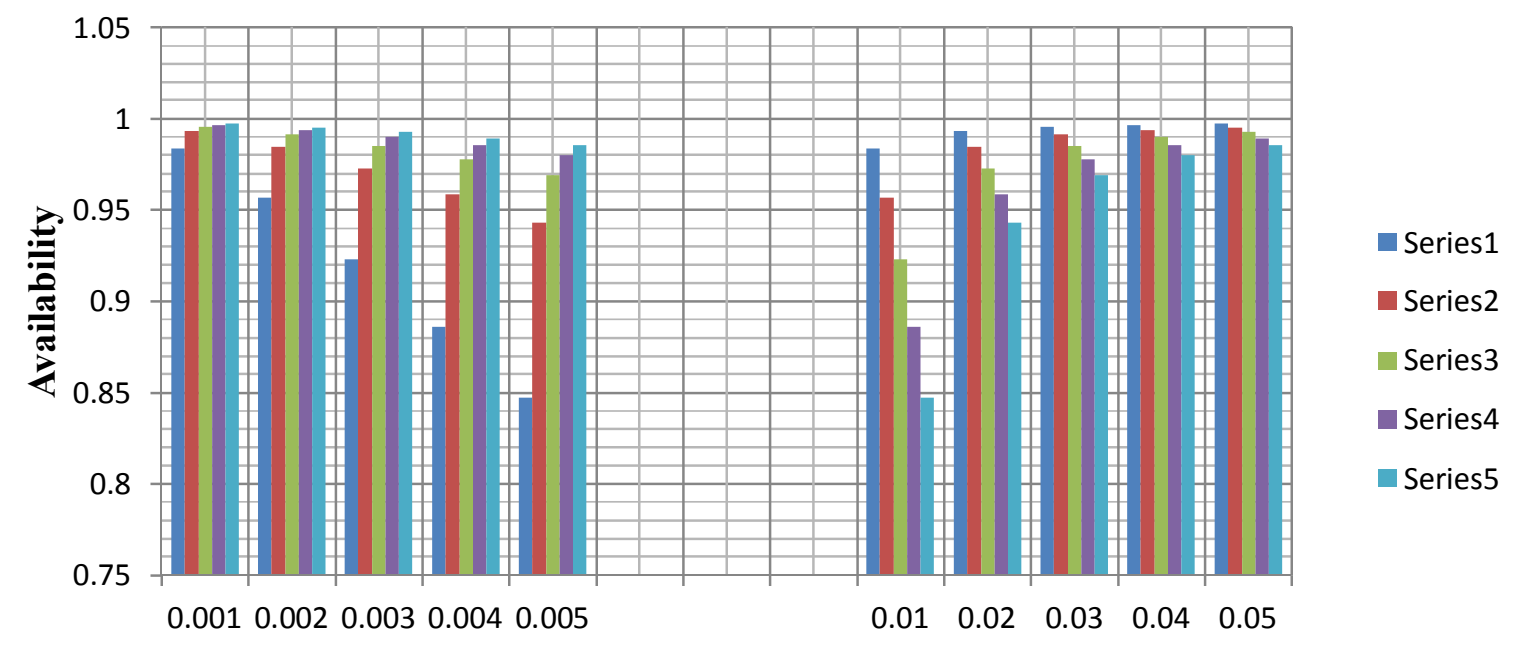

Failure rate

Repair rate

Fig. 5. Effect of Failure and Repair Rates of Primary Air Fan on Availability ( $\left.A_{v}\right)$

\section{Conclusions}

The availability matrices are developed and shown in the form of graphs (Figs. 2-5). These figures facilitate the maintenance decisions to be made at critical points where repair priority should be given to any particular subsystem of the system. It is clear from figures 2-5 that on doubling the values of baseline failure and repair rates of all the subsystems, the failure of "Primary Air Fan" affect system availability at a rapid rate, while failure of "Air Heater" have little effect on the availability of the system concerned among these four subsystems. Therefore, on the basis of repair rates, the maintenance priority should be given as per following order:

1) Primary air fan $\left(\mathrm{P}_{\mathrm{f}}\right)$

2) Forced draft fan $\left(F_{d}\right)$

3) Induced draft fan $\left(I_{d}\right)$

4) Air heater $\left(A_{h}\right)$

\section{References}

Abdelaziz, A. R. (1997). Reliability evaluation in operational planning of power systems. Electric Machines and Power Systems, 25 (4), 419-428.

Arora, N., \& Kumar, D. (1997). Availability analysis of steam and power generation systems in the thermal power plant. Microelectronics Reliability, 37 (5), 795-799.

Balaguruswamy, E. (1984). Reliability Engineering. Tata McGraw Hill: New Delhi.

Barabady, J., \& Kumar, U. (2007). Availability allocation through importance measures. International journal of quality \& reliability management, 24(6), 643-657. 
Blischke, W. R., \& Murthy, D. N. P. (2003). Case Studies in Reliability and Maintenance. USA: John wiley \& sons, Inc.

Clifton, R.H. (1974). Principles of Planned Maintenance. Edward Arnold Publishers: London.

Cochran, J.K., Murugan, A., \& Krishnamurthy V. (2001). Generic Markov models for availability estimation and failure characterization in petroleum refineries. Computers and Operations Research, 28(1), 1-12.

Dhillon, B. S. (1983). Reliability engineering in systems design and operation. New York:Van NostrandReinhold.

Galikowsky, C., Sivazlian, B.D., \& Chaovalitwongse, P. (1996). Optimal redundancies for reliability and availability of series systems. Microelectronics Reliability, 36(10), 1537-1546.

Garg, S., Singh, J., \& Singh, D.V. (2010). Availability and maintenance scheduling of a repairable blockboard manufacturing system. International Journal of reliability \& safety, 4(1), 104-118.

Gupta, P., Lal, A.K., Sharma, R.K., \& Singh, J. (2005). Numerical analysis of reliability and availability of the series processes in butter oil processing plant. International Journal of Quality \& Reliability Management, 22(3), 303-316.

Gupta, P., Lal, A.K., Sharma, R.K., \& Singh, J. (2007). Analysis of reliability and availability of serial processes of plastic-pipe manufacturing plant: A case study. International Journal of Quality \& Reliability Management, 24(4), 404-419.

Haghifam, M.R,, \& Manbachi, M. (2011). Reliability and availability modeling of combined heat and power systems. Electrical Power and Energy Systems, 33(3), 385-393.

Kumar, D., \& Pandey, P. C. (1993). Maintenance planning and resource allocation in urea fertilizer plant. Quality and reliability Engineering International, 9(5), 411-423.

Kumar, R., Sharma, A.K., \& Tewari, P.C. (2012). Markov approach to evaluate the availability simulation model for power generation system in a thermal power plant. International journal of industrial engineering \& computations, 3(5), 743-750.

Lieberman, N. P. (1973). Process Design for Reliable Operations. Gulf Publishing Company: Huston, TX.

Purbolaksono, J. Ahmad, J., Khinani, A., Ali, A.A., \& Rashid, A.Z. (2010). Failure case studies of SA213-T22 steel tubes of boiler through computer simulations. Journal of Loss Prevention in the Process Industries, 23 (1), 98-105.

Sharma, A.k., \& Tewari, P.C. (2009). Performance evaluation and economic analysis of a steam thermal power plant. South African Journal of Industrial Engineering, 30(1), 133-146.

Shayan, M.E. (1986). A probabilistic model of coal-burning power plant. IEEE Transactions on

Reliability, R-35 (5), 488-493.

Shooman, M.L. (1961). Probabilistic Reliability: An Engineering Approach. Tata McGraw-Hill Edition: New Delhi, India.

Singh, J., Pandey, P.C., \& Kumar, D. (1990). Designing for reliable operation of urea synthesis in the fertilizer industry. Microelectronics Reliability, 30(6), 1021-1024.

Srinath, L. S. (1994). Reliability Engineering. 3rd edition, New Delhi, India. East-West Press Pvt. Ltd.

Tan, J. S., \& Kramer, M. A. (1997). A general framework for preventive maintenance optimization in chemical process operations. Computers \& Chemical Engineering, 21(12), 1451-1469. 


\section{Appendix-A}

$$
\begin{aligned}
& P_{0}^{\prime}(t)+\left(f_{A_{h}}+f_{I_{f}}+f_{F_{f}}+f_{P_{f}}\right) P_{0}(t)=r_{A_{h}} P_{5}(t)+r_{I_{f}} P_{1}(t)+r_{F_{f}} P_{7}(t)+r_{P_{f}} P_{3}(t) \\
& P_{1}^{\prime}(t)+\left(r_{I_{f}}+f_{I_{f}}+f_{F_{f}}+f_{P_{f}}\right) P_{1}(t)=r_{F_{f}} P_{10}(t)+r_{P_{f}} P_{12}(t)+r_{I_{f}} P_{0}(t)+r_{I_{f}} P_{11}(t) \\
& P_{2}^{\prime}(t)+\left(f_{I_{f}}+f_{P_{f}}\right) P_{2}(t)=r_{I_{f}} P_{3}(t)+r_{P_{f}} P_{1}(t) \\
& \cdots \\
& P_{20}^{\prime}(t)+r_{F_{f}} P_{20}(t)=f_{F_{f}} P_{7}(t)
\end{aligned}
$$

For steady state availability, initial conditions at time $\mathrm{t} \Rightarrow 0$ are $P_{i}(t)=1$ for $\mathrm{i}=0$, otherwise $P_{i}(t)=0$

The system is required to be available for long duration of time. Now put $d / d t=0$ for $\mathrm{t} \Rightarrow \infty$ into all differential equations (A.1) to (A.21). Thus

$$
\begin{aligned}
& \left(f_{A_{h}}+f_{I_{f}}+f_{F_{f}}+f_{P_{f}}\right) P_{0}=r_{A_{h}} P_{5}+r_{I_{f}} P_{1}+r_{F_{f}} P_{7}+r_{P_{f}} P_{3} \\
& \left(r_{I_{f}}+f_{I_{f}}+f_{F_{f}}+f_{P_{f}}\right) P_{1}=r_{F_{f}} P_{10}+r_{P_{f}} P_{12}+r_{I_{f}} P_{0}+r_{I_{f}} P_{11} \\
& \ldots \\
& r_{F_{f}} P_{20}=f_{F_{f}} P_{7}
\end{aligned}
$$

Solving the above equations, we get:

$$
\begin{aligned}
& P_{1-8}=L_{1-8} P_{0} P_{9}=K_{2} L_{8} P_{0}, P_{10}=K_{3} L_{8} P_{0} P_{11}=K_{2} L_{1} P_{0} P_{12}=K_{4} L_{2} P_{0} P_{13}=K_{2} L_{2} P_{0} P_{14}=K_{4} L_{3} P_{0}, P_{15}=K_{1} L_{4} P_{0}, P_{16}=K_{4} L_{4} P_{0}, \\
& P_{17}=K_{1} L_{5} P_{0}, P_{18}=K_{3} L_{6} P_{0}, P_{19}=K_{1} L_{6} P_{0} P_{20}=K_{3} L_{7} P_{0}
\end{aligned}
$$

Now using normalizing conditions i.e. sum of all the probabilities is equal to one, we get:

$$
\begin{aligned}
& \sum_{i=0}^{i=20} P_{i}=1 \\
& P_{0}=\left[1+\sum_{j=1}^{8} L_{j}+K_{2} L_{8}+K_{3} L_{8}+K_{2} L_{1}+K_{4} L_{2}+K_{2} L_{2}+K_{4} L_{3}+K_{1} L_{4}+K_{4} L_{4}+K_{1} L_{5}+K_{3} L_{6}+K_{1} L_{6}+K_{3} L_{7}\right]^{-1} \\
& \text { where, } K_{1}=f_{A_{h}} / r_{A_{h}}, K_{2}=f_{I_{f}} / r_{I_{f}}, K_{3}=f_{F_{f}} / r_{F_{f}}, K_{4}=f_{P_{f}} / r_{P_{f}} \\
& L_{1}=\left(f_{I_{f}}+f_{P_{f}} R_{1}+f_{P_{f}} R_{2} R_{16}+R_{16} f_{F_{f}}\right) /\left(S_{1}-f_{P_{f}} R_{2} R_{17}-R_{16} f_{F_{f}}\right), L_{2}=R_{1}+R_{2} L_{8}+R_{0} L_{3}, L_{3}=R_{3}+R_{4} L_{8}+R_{5} L_{4} \\
& L_{4}=R_{6}+R_{7} L_{8}+R_{9} L_{5}, L_{5}=R_{10}+R_{11} L_{8}+R_{12} L_{6}, L_{6}=R_{13}+R_{14} L_{8}+R_{15} L_{7}, L_{7}=T_{20}+T_{21} L_{8}, L_{8}=R_{16}+R_{17} L_{1} \\
& S_{1}=r_{I_{f}}+f_{F_{f}}+f_{P_{f}}, S_{2}=f_{I_{f}}+f_{P_{f}}, S_{3}=f_{A_{h}}+f_{I_{f}}+r_{P_{f}} S_{4}=f_{A_{n}}+f_{P_{f}}, S_{5}=r_{A_{h}}+f_{F_{f}}+f_{P_{f}}, S_{6}=f_{A_{n}}+f_{F_{f}}, S_{7}=f_{A_{h}}+f_{I_{f}}+r_{F_{f}}, S_{8}=f_{I_{f}}+f_{F_{f}} \\
& R_{0}=T_{3} / T_{1}, R_{1}=T_{0} / T_{1}, R_{2}=T_{2} / T_{1}, R_{3}=T_{5} / T_{4}, R_{4}=T_{6} / T_{4}, R_{5}=N_{7} / T_{4}, R_{6}=T_{8} / T_{7}, R_{7}=T_{9} / T_{7}, R_{9}=T_{10} / T_{7}, \\
& R_{10}=T_{12} / T_{11}, R_{11}=T_{13} / T_{11}, R_{12}=T_{14} / T_{11}, R_{13}=T_{16} / T_{15}, R_{14}=T_{17} / T_{15}, R_{15}=T_{18} / T_{15}, R_{16}=T_{23} / T_{22}, R_{17}=T_{24} / T_{22} \\
& T_{0}=f_{P_{f}} f_{I_{f}} / S_{2} S_{1}, T_{1}=\left(1-f_{P_{f}}^{2} f_{I_{f}} / S_{2} S_{1}\right), T_{2}=f_{P_{f}} f_{F_{f}} / S_{2} S_{1}, T_{3}=f_{I_{f}} / S_{2}, T_{4}=\left(1-T_{3} f_{I_{f}} / S_{3} T_{1}\right), T_{5}=f_{P_{f}} / S_{3} \text {, } \\
& T_{6}=f_{I_{f}} T_{2} / S_{3} T_{1}, T_{7}=\left(1-f_{A_{n}} N_{7} / S_{4} T_{4}\right), T_{8}=f_{A_{n}} T_{5} / S_{4} T_{4}, T_{9}=f_{A_{n}} T_{6} / S_{4} T_{4}, T_{10}=f_{P_{f}} / S_{4}, T_{11}=\left(1-f_{P_{f}} T_{10} / S_{5} T_{7}\right) \text {, } \\
& T_{12}=\left[\left(f_{A_{n}} / S_{5}\right)+\left(f_{P_{f}} T_{8} / S_{5} T_{7}\right)\right], T_{13}=f_{P_{f}} T_{9} / S_{5} T_{7}, T_{14}=f_{F_{f}} / S_{5}, T_{15}=\left(1-T_{14} f_{F_{f}} / S_{6} T_{11}\right), T_{16}=T_{12} f_{F_{f}} / S_{6} T_{11} \text {, } \\
& T_{17}=f_{F_{f}} T_{13} / S_{6} T_{11}, T_{18}=f_{A_{n}} / S_{6}, T_{19}=\left(1-f_{A_{n}} T_{18} / S_{7} T_{15}\right), T_{20}=\left[\left(f_{F_{f}} / S_{7}\right)+\left(f_{A_{n}} T_{16} / S_{7} T_{15}\right)\right] \text {, } \\
& T_{21}=\left[\left(f_{A_{h}} T_{17} / S_{7} T_{15}\right)+\left(f_{I_{f}} / S_{7}\right)\right], T_{22}=\left[1-\left(f_{I_{f}} T_{21} / S_{8} T_{19}\right)\right], T_{23}=f_{I_{f}} T_{20} / S_{8} T_{19}, K_{2}=f_{I_{f}} / r_{I_{f}}, T_{24}=f_{F_{f}} / S_{8}, N_{7}=f_{A_{h}} / S_{3}
\end{aligned}
$$

